Article

\title{
Attaching Hollywood to a Surveillant Assemblage: Normalizing Discourses of Video Surveillance
}

\author{
Randy K. Lippert * and Jolina Scalia \\ Department of Sociology, Anthropology, and Criminology, University of Windsor, Windsor, ON N9B 3P4, Canada; \\ E-Mails: lippert@uwindsor.ca (R.L.), scalia3@uwindsor.ca (J.S.) \\ * Corresponding author
}

Submitted: 5 April 2015 | In Revised Form: 5 June 2015 | Accepted: 15 June 2015 |

Published: 20 October 2015

\begin{abstract}
This article examines video surveillance images in Hollywood film. It moves beyond previous accounts of video surveillance in relation to film by theoretically situating the use of these surveillance images in a broader "surveillant assemblage". To this end, scenes from a sample of thirty-five (35) films of several genres are examined to discern dominant discourses and how they lend themselves to normalization of video surveillance. Four discourses are discovered and elaborated by providing examples from Hollywood films. While the films provide video surveillance with a positive associative association it is not without nuance and limitations. Thus, it is found that some forms of resistance to video surveillance are shown while its deterrent effect is not. It is ultimately argued that Hollywood film is becoming attached to a video surveillant assemblage discursively through these normalizing discourses as well as structurally to the extent actual video surveillance technology to produce the images is used.
\end{abstract}

\section{Keywords}

assemblages; discourses; film; normalization; surveillance; video

\section{Issue}

This article is part of the special issue "Surveillance: Critical Analysis and Current Challenges", edited by James Schwoch (Northwestern University, USA), John Laprise (Independent Researcher) and Ivory Mills (Northwestern University, USA).

(C) 2015 by the authors; licensee Cogitatio (Lisbon, Portugal). This article is licensed under a Creative Commons Attribution 4.0 International License (CC BY).

\section{Introduction}

When a video surveillance image of the Washington, D.C. subway platform helped identify an intern's murderer in the State of Play, when footage of a man with a prosthetic leg entering airport Customs helped identify an elusive assassin in The International, and when images of a lime drink ordered from a Las Vegas blackjack table revealed an illegal card counting plot in 21, Hollywood expressed that video surveillance ${ }^{1}$ is a widespread, useful investigative tool that can yield positive benefits. At the same time video surveillance continues to spread largely unheeded (Doyle et al., 2012). Al-

1 We use "video surveillance" rather than "CCTV", since this technology is no longer exclusively closed circuit or has much to do with television (Doyle et al. 2012, p. 5). ready commonplace in malls, banks, convenience stores, casinos and airports by the 1980s, it has since appeared in taxi-cabs, transit stations, trains, buses, fast food restaurants, supermarkets, campuses, schools, private residences, and even within police officers' vehicles and uniforms (Carroll, 2013; Dinkes et al., 2009; Doyle \& Walby, 2012; Monahan, 2006; SCAN, 2009; Walby, 2006). Video surveillance is now encountered virtually everywhere, anytime, its images almost instantaneously reproduced and widely disseminated by almost anyone with internet access, a device, and data file-sharing capabilities. This astonishingly rapid proliferation of video surveillance and its generated images, as with many newer forms of surveillance, is troubling because it can seriously threaten personal privacy and can reproduce social inequalities when dis- 
advantaged groups defined by race/ethnicity, gender, class, or sexual orientation are disproportionately targeted (Doyle et al., 2012; Lippert, 2009; Monahan, 2010, p. 90; SCAN, 2009). This lack of public opposition to video surveillance's proliferation, with or without fair notification (Lippert, 2009) or built-in privacy-by-design protections (Lippert \& Walby, 2015), implies many ignore, forget, or are unaware that these systems pose serious threats. But what is perhaps most puzzling is the wide embrace of video surveillance systems, despite ambiguous evidence of effectiveness in halting or reducing the illegal or other undesired behavior it aims to curtail (see Doyle et al., 2012; SCAN, 2009). Independent and government studies, for example, often suggest video surveillance is quite limited as a violent crime prevention measure (Verga, 2010, p. 10).

How video surveillance and its images are widely understood to be used and experienced may be a more important driver than their actual effectiveness in reducing crime or other unwanted conduct. Plainly one process affecting these understandings is when video surveillance images that are produced in myriad actual settings (such as banks or convenience stores) find their way into television news programs and onto news media websites for purposes of entertainment (or "fun", see Bauman et al., 2014). Another entertainment-related use that may lead to wider acceptance, however, entails featuring video surveillance and its images in fictional Hollywood film. The film scenes depicting video surveillance images, such as those above, may normalize the spread and intensification of video surveillance. This article explores video surveillance images in Hollywood film to discern key normalizing discourses and lend understanding to how Hollywood film may be becoming attached to a video surveillance assemblage.

\section{Surveillance Assemblage, Normalization, and Expression}

Video surveillance's growth is part and parcel of the broader proliferation of myriad surveillance technologies in "surveillance societies" (Murakami-Wood \& Webster, 2009, 2011) where "the gaze is ubiquitous, constant, inescapable" (Lyon, 2007, p. 25). By surveillance we mean "the systematic monitoring of people or groups in order to regulate or govern their behavior" (Monahan, 2011, p. 498). The growing "surveillance studies" literature seeks to understand how new forms of surveillance scrutinize populations (Lyon, 2002, p. 2). But this literature has thus far tended to neglect normalization (Murakami-Wood \& Webster, 2009, 2011), the process by which these forms of surveillance become widely accepted in society.

An emergent model of surveillance in surveillance studies is the assemblage (Haggerty \& Ericson, 2000; Lippert, 2009; Lippert \& Wilkinson, 2010; Wilkinson \&
Lippert, 2011; Murakami-Wood, 2013), a surveillance entity that involves merging previously distinct elements. Adapted from the philosophy of Deleuze and Guattari (1987), here surveillance is "rhizomatic", its growth occurs "across a series of interconnected roots which throw up shoots in different locations" rather than hierarchically (Haggerty \& Ericson, 2000, p. 614). An assemblage works "by abstracting human bodies" from particular sites and sorting them into separate channels; they are then reassembled elsewhere as "data doubles" or entities of pure information that are amenable to closer scrutiny and analysis (Haggerty \& Ericson, 2000 , p. 606). This examination and calculation occurs at myriad sites to inform strategies of control (Haggerty \& Ericson, 2000, p. 613). Surveillant assemblages do not, however, reflect centralized systematic control as evinced in George Orwell's "Big Brother" centralized state or Michel Foucault's panoptic central tower (Haggerty \& Ericson, 2000). Foucault's panopticon in particular has been stretched beyond recognition to fit new forms and contexts of surveillance (Haggerty, 2006; see also Zimmer, 2011). For example, its notions of soul-training through discipline in enclosed spaces (see Foucault, 1977) are hopelessly out of sync with how much contemporary surveillance operates across and in spite of spatial barriers (Haggerty, 2006).

But there is more to surveillant assemblages than how they operate. Thus, assemblages tend to be propelled and shaped by specific governmental logics (Lippert, 2009). Of pertinence here is the "precautionary logic" that is associated with neo-liberalism and which presupposes definite "limits of science and technology" in yielding certainty about the future (Ericson, 2007, p. 22). As it enters liberal democratic institutions this logic undercuts trust, raises suspicion and doubt, and fuels criminalization (Ericson, 2007, pp. 21-24). It also overrides longstanding criminal law principles, such as the presumption of innocence (Ericson, 2007, pp. 23-24), thus halting the traditional practice of equating uncertainty with innocence (e.g., convicting persons of criminal offences only when guilt is "beyond a reasonable doubt"). As this logic spreads, surveillant assemblages emerge as a major form of "counter law" or "law against law" (Ericson, 2007, p. 33) to confront the often worst conceivable future outcome, regardless of uncertainty over whether it will ever occur. Perhaps even more relevant to this paper is the mass media logic that demands access to "the real" and which is perhaps best evinced in the remarkable growth of reality television during at least the past two decades (Lippert \& Wilkinson, 2010, p. 136). Increasingly viewers are thought to demand, even crave, this access, however illusory it may be (see, for example, Doyle's (2003) insightful analysis of the supposed realism of the long running FOX television program, "Cops").

Surveillant assemblages do not emerge separate from how their elements are expressed and represent- 
ed. Consistent with this, Kammerer (2012, p. 105) writes: "The surveillant imaginary is not external to the working of surveillance, but intrinsically linked to its functioning". Where assemblages are concerned, this means, as Bogard (2006, p. 107) explains, "[e]very assemblage must be described both in terms of its content...and its expression...That is, one must examine not only what the assemblage does, but also what it says". How is Hollywood film becoming attached to a video surveillant assemblage? If Hollywood film makes statements about video surveillance when using these images, what does it say?

Film is a powerful medium and like television's effects on violence (e.g., Jamieson \& Romer, 2014), it has undergone much study about its relationship to real world problematic behaviors and events too numerous to detail here. It is important to note, however, that film is neither merely a mirror of the real world, representing surveillance technologies and processes in realistic ways, nor does it necessarily directly affect real world acceptance thereof. Rather, surveillance in film and surveillance in social institutions or the broader society influence one another in ways often difficult to unravel. To suggest film influences the normalization of surveillance demands at a minimum an exploration of how it does this, that is, through what specific discourses. To think of Hollywood film as part of a surveillant assemblage is to begin to move beyond film's representational role. We argue that there is a sense in which film is not merely representing video surveillance in the ways identified below but is actually attaching itself to it. Film may be an element of rather than merely a mirror reflecting complex video surveillance assemblages.

To be normalized, the implanting or implementation of a technology and related processes must receive little or no effective resistance. Normalization entails discourses or "groups of statements which structure the way a thing is thought and the way we act on the basis of that thinking..." (Rose, 2007, p. 142). These discourses express and structure how we understand and act upon an increasingly watched world and the technologies comprising it. Recent work has begun to situate video surveillance in relation to surveillant assemblages (Lippert, 2009; Lippert \& Wilkinson, 2010; Wilkinson \& Lippert, 2012). One way of conceiving of normalization is as a decidedly overlooked element of these assemblages.

This paper's purpose is to move beyond previous research by approaching the presence of video surveillance images in Hollywood films as elements of a video surveillant assemblage. Specifically, it seeks to extend thinking about surveillance and film by exploring dominant discourses of video surveillance, illuminating the complexity of video surveillance image use in Hollywood film, and theoretically situating film use in a surveillant assemblage. In so doing we seek to fill a gap in surveillance studies about normalization via film, an effort we think is overdue.

The remainder of this article unfolds in five parts. We first discuss previous research on surveillance and film. After discussing our method, we next elaborate results of our exploratory inquiry by showing first that video surveillance is appearing in film more often; it is increasingly worked into film in various ways. We then reflect on this incorporation of video surveillance images to identify the discourses impressed upon viewers in a sample of Hollywood films and how these may contribute to normalization. We then take up how Hollywood is attached to a video surveillance assemblage and conclude by discussing the implications of these findings for existing literature and future research.

\section{Previous Research on Surveillance and Film}

Most of what is known about surveillance comes from media discourses (Norris \& Armstrong, 1999, p. 63), which typically represent video surveillance in positive terms (see Andrejevic, 2004; Barnard-Wills, 2011; Norris \& Armstrong, 1999). Reality television (see Doyle, 2006; McCahill, 2003), in particular, has led citizens to become accustomed to surveillance in everyday life, even to enjoy it; it has "train[ed] our eyes and minds for surveillance" (Murakami-Wood \& Webster, 2009, p. 264). Television's entertaining or "fun" quality is a key driver of surveillance technologies (Albrechtslund \& Dubbeld, 2005).

The broad theme of surveillance in Hollywood films has been explored, along with how its ethical dilemmas, including those relating to privacy, are portrayed (Albrechtslund, 2008). Turner's (1998) research, for example, analyzed a large but now dated sample of Hollywood films. He argued the overabundance of surveillance themes in media "transforms the will and practice of the surveillance society into a spectacle" (1998, p. 107), renders viewers passive, and leads to acceptance of surveillance technology. Since then Levin (2002) noticed Hollywood films were increasingly using recorded video surveillance images to accompany narration, such as in Thelma and Louise. Though his focus is beyond video surveillance, Levin (2002, p. 582) was unique in suggesting that film narration has "effectively become synonymous with surveillant" expression and that there is increasingly a structural mutually constitutive tether between surveillance technologies and film. Although not invoking the assemblage concept, and based on only a few films, Levin's assertion is nonetheless supportive of our analysis that follows. Zimmer (2011) similarly considers the rise of surveillance themes in film narratives by focusing on early $20^{\text {th }}$ Century short films and Alfred Hitchcock's Rear Window. Suggestive for our analysis below too, Zimmer argues not only that surveillance technologies as depicted are inconsistent with the panopticon (also implied by Gad 
\& Hansen (2013) as noted below), but that surveillance narratives in film "should be viewed not just as 'reflections' of an increasingly-centred media, but themselves as practices of surveillance" (Zimmer, 2011, p. 439; original emphasis). This remark is consistent with our assertion later: there is a more structural or material attachment between Hollywood film and video surveillant assemblages, that in this respect at least there is sometimes no clear division between them.

Such accounts above partially speak to normalization and offer compelling, insightful analyses on which to build, although more detailed attention to more recent Hollywood films is needed. Video surveillance specifically has only begun to be studied in film, despite hints of its growing presence there. Most scholars researching video surveillance in cinema have sought to discover themes by analyzing a few films or a single film, for example, Red Road (Lake, 2010) or Faceless (Zeilinger, 2012). While these latter efforts have focused on somewhat obscure films, with limited viewership, they nonetheless have uncovered key themes of video surveillance, which can be investigated further. Thus, Lake (2010) effectively underscores in her analysis of Red Road, whose protagonist is a woman video surveillance operator, the notion that surveillers in Hollywood film are almost always White men in professional roles. Lake's attention to gender in relation to video surveillers is particularly significant in highlighting the fact that normalization is as much about who can acceptably and properly use video surveillance technology and reap its rewards as about those who become its targets. Similarly, Zeilinger (2012) highlights the near complete lack of critical reflection on video surveillance in film via a compelling analysis of the appropriation method evident in Faceless, a film created entirely by appropriating existing video surveillance footage to effectively challenge the growing video surveillance assemblage.

Of most pertinence to this paper, because of a closer focus on video surveillance in Hollywood film, however, are Gad and Hansen (2013) and Kammerer (2004) (from the perspective of film studies, see also Stewart (2012) regarding two 2012 Hollywood films, Total Recall and the Bourne Legacy). Gad and Hensen (2013, p. 153) argue that a key theme expressed by the film, Minority Report, is that prevention is achieved when involving a "complex assemblage" of humans and surveillance technologies (rather than suggesting that prevention is somehow linked, for example, to a panopticon). Unfortunately they do not extend their argument further to suggest films like Minority Report are discursively or structurally attached to that same assemblage. Kammerer (2004) analyzes three films (Enemy of the State, Minority Report, and Panic Room) with surveillance as a primary theme. He found a major discourse was the flawlessness of surveillance technology. According to Kammerer (2004), these films attest to technological infallibility; only human use of surveillance technology is error prone. Kammerer argued, contrary to Turner (1998), that Hollywood films like these can effectively raise vital issues about video surveillance in society, suggesting not all Hollywood film necessarily contributes to normalization (see also Kammerer, 2012, p. 105). We do not disagree with this assessment of film's critical potential (see also Marks, 2005), especially when considered in conjunction with brilliantly-crafted critical films like Faceless and Red Road. Yet, we assert a larger, broader sample of contemporary Hollywood films needs to be examined to discover more about whether and how they may contribute to normalization and to aid thinking about how they may be becoming attached to surveillant assemblages. This article therefore builds upon this insightful but somewhat mottled body of previous research from social science and the humanities by exploring a larger and broader sample of scenes from contemporary Hollywood films of multiple genres to discover relevant discourses and thereby lend understanding to popular cinema's messages to viewers specifically about video surveillance; how they may be contributing to its normalization through these expressions; as well as how they are becoming part of a video surveillance assemblage.

\section{Method}

To determine whether video surveillance's presence in film is proliferating we examined the IMDB, a comprehensive online film database ${ }^{2}$, for films from the 1960 s to the present categorized as featuring "CCTV" 3 surveillance. This examination was not intended to be exhaustive since other databases and keywords could have been used. Rather, it was envisioned as illustrative for this article's modest purposes. A drawback of this procedure was that films were categorized in IMDB only if CCTV surveillance was a prominent theme and thus this understandably underestimated its presence considerably. This was also a rawer measure than a rate of video surveillance inclusion (i.e., surveillance images per film), and admittedly there were more Hollywood films produced in each decade after the 1960s. Nonetheless, this procedure provided an initial empirical measure of video surveillance's growing presence in Hollywood film beyond mere impressions and it is one which might prime the pump for the flow of more refined procedures in this neglected realm.

To explore the discourses about video surveillance in Hollywood film our approach differed from most previous analyses of surveillance in film in that we examined 35 Hollywood films screened in North Ameri-

\footnotetext{
2 http://www.imdb.com.

${ }^{3}$ We used "CCTV" in this instance because that is what was used in the IMBD database more often than "video surveillance".
} 
can theaters from 1998 to 2015 (see Appendix 14). We assumed Hollywood films screened in major theaters would eventually reach a larger viewership than straight-to-DVD films or more obscure films like Faceless, and were thus more apt to contribute to normalization. This is also a period during which video surveillance in film, based on our measure above, has expanded considerably. Rather than a random sample, we purposely included action, comedy, drama, horror, and thriller genres identified using IMDB. Given limited funding available, the cost of securing the films for analysis was also a consideration since some films falling within the parameters above were simply unavailable or too costly to acquire.

Our study then employed discourse analysis of the scenes (see Rose, 2007). This method promised to illuminate how Hollywood film represents video surveillance and how the former might contribute to the latter's normalization through dominant messages. Our analysis identified dominant discourses via two processes: open and focused coding. The open coding began with analyzing without previously formulated categories (Babbie \& Benaquisto, 2002, p. 382). This was followed by focused coding whereby we subjected images to predetermined themes of interest from open coding or extant literature described above. The results of these procedures are discussed below.

4 Though popular, some Hollywood films in the sample undoubtedly will be unknown to at least some readers. Unfortunately there is nowhere near enough space for a synopsis of each film; the reader is therefore encouraged to view unfamiliar films or consult online plot summaries via IMBD.com or rottentomatoes.com, among other sources.

\section{Results}

\subsection{Growth of Video Surveillance in Hollywood Film}

Video surveillance is increasingly present in Hollywood film. Our examination of the IMDB using the method described earlier revealed that, especially since 1999, the number of Hollywood and other films featuring video surveillance as a key element has increased dramatically as shown below (see Figure 1 ) and is accelerating during a time when video surveillance is fast proliferating in society. There were more films (8) featuring video surveillance in 2013 than any previous year. In the next section we examine the discourses concerning video surveillance.

\subsection{Discourses of Video Surveillance in Hollywood Film}

Our sample of 35 films included comedies like American Pie and Hall Pass and dramas like 21 and The Judge in which viewers may not readily expect to find video surveillance compared to, for example, thriller or crime genres. From our analysis emerged four dominant discourses about video surveillance: 1) Video Surveillance can Identify and Locate People to Advantage; 2) Video Surveillance need not Raise Privacy Concerns or be Resisted; 3) Only some People are Video Surveillance Competent; and 4) Neglect Video Surveillance and its Malfunctions at your Peril. While dominant in our sample, these discourses are not necessarily present in equal proportions across it. Each is elaborated below via illustrative scenes.

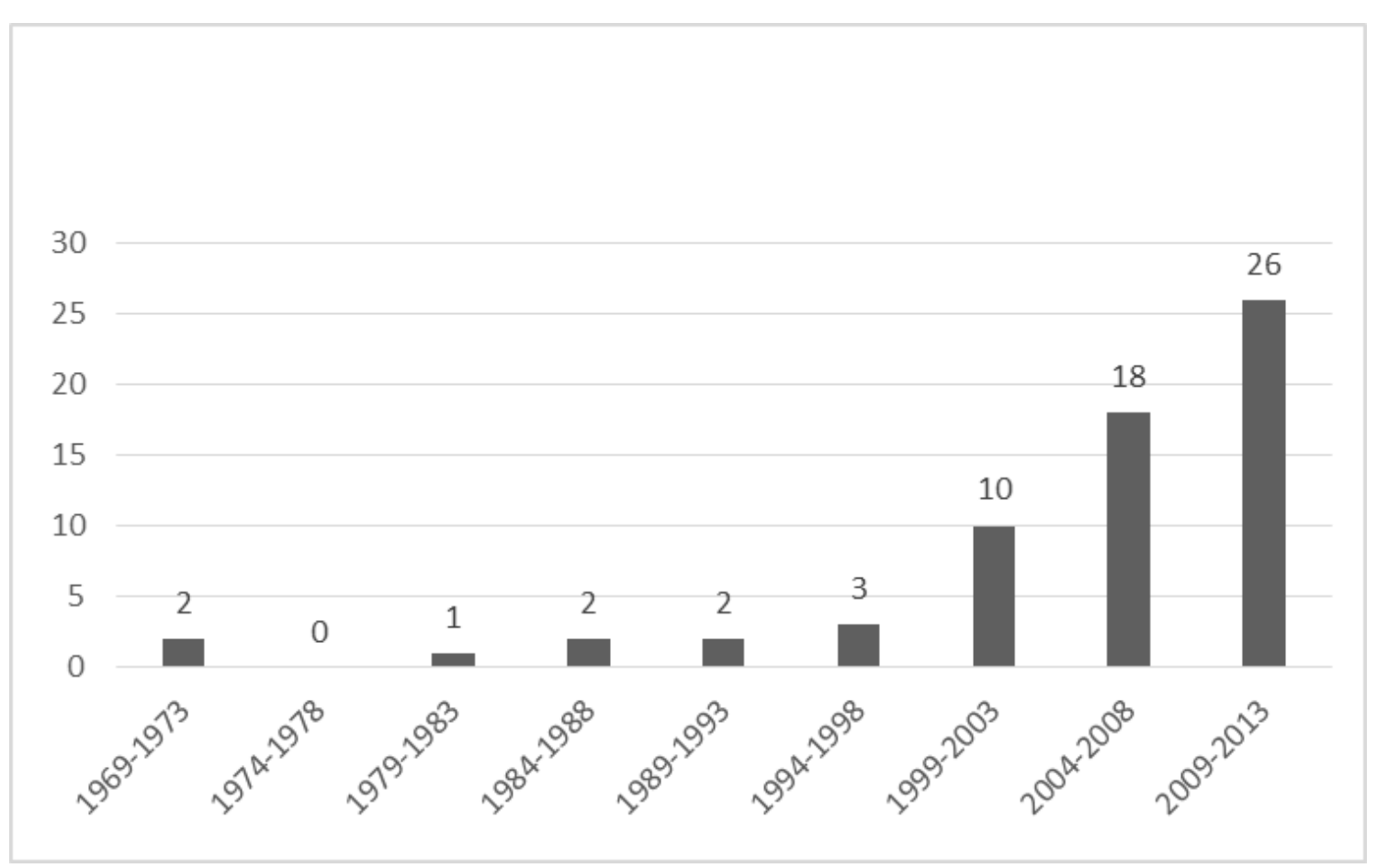

Figure 1. Number of popular films with video surveillance as plot element, 1969-2013. 


\subsubsection{Video Surveillance Can Identify and Locate People to Advantage}

Scenes from 23 films suggested video surveillance can effectively identify or locate persons of interest to advantage or to serve particular interests. Our analysis revealed when this occurred it often lead to a major plot change, most often by discovering a person's true identity or culpability consistent with scenes described below. For example, in Enemy of the State, Robert Dean is shopping for a gift for his wife. There he encounters an old friend who frantically requests Dean's help and then exits the store. Shortly after, Dean discovers his friend was killed outside. The corrupt government agents responsible for the murder managed to secure video surveillance images showing the friend dropping an item into Dean's shopping bag. Dean then becomes a person of interest. In Showtime, detectives are watching a television show in their homes. While on the phone, one detective glances at the television and notices a person employed as a police department staffer in a bar with a known arms dealer. This image identifies a suspect which leads detectives to solve the case. In Bourne Ultimatum, the main character Bourne is in a train station using a cell phone to instruct a reporter to avoid being spotted by video surveillance. The reporter nonetheless draws attention to himself by running through the crowd and is identified via video surveillance by government agents and assassinated shortly thereafter while Bourne, whose location was unknown to this point in the film, is also identified in the crowd via video surveillance.

In other films too, persons were identified and then followed, typically using multiple video surveillance cameras. In Snake Eyes, after locating a person of interest on the casino floor via the security room's video surveillance monitors, Rick Santoro races to that location while using a "walkie-talkie" to stay connected to a guard in the security room. The guard directs Santoro to the person of interest using multiple casino surveillance cameras. In these films, video surveillance is seen yielding crucial information, such as a key person's location at a particular time. In several other films it is not a person of interest being sought but instead a vital object or valuable resource. In The Italian Job, a gang of thieves searches for one of three trucks containing gold bricks. As each truck passes through the gaze of video surveillance, the three images are compared to discern which truck is lowest to the ground and thus weighed down by an especially heavy load. This visual information helps reveal the gold's location. Across these scenes this information is always seen to be used to the advantage of the person accessing the images, thereby creating a decidedly positive association with video surveillance.

An overwhelming majority of surveillance images in the films did not lead to conventional criminal justice via arrests and convictions. However, video surveillance often effectively aided investigators pursuing these goals. In most films the discovery of suspects or persons of interest occurred because of video surveillance's capacity to provide visual information to solve a case. For instance, in State of Play, video surveillance footage of a congressional aide who allegedly committed suicide by stepping in front of a subway train is examined by Della Frye, a news reporter. Frye recognizes a man in the subway platform's video surveillance images whom she believes is implicated in murdering the aide by pushing her in the train's path instead. Frye combines this image with a newspaper photograph showing this man accompanying a congressman with whom the aide had closely worked, thereby implicating the congressman in her death. Thus, video surveillance in Hollywood film is rarely portrayed as possessing an unyielding or unlimited capacity to identify and locate a "bad guy" leading to their capture, punishment or demise. It is only rarely presented as a completely effective retroactive tool to bring criminals to justice on its own. Nonetheless, video surveillance is used consistent with the precautionary logic. Just in case extreme-but in real life, exceedingly rare-instances of murder and robbery may occur, it is plainly prudent to have these systems in place for later advantage if necessary.

Main characters use video surveillance of other characters to advantage in Hollywood film too, a practice sometimes called "lateral" surveillance (see Andrejevic, 2005). How characters were able to create advantage varied. In Inside Man, police detective Keith Frazier becomes suspicious of bank robbers who seem to be buying time during a hostage situation in the bank. Recognizing Frazier is suspicious, robbers then position video surveillance to record activity directly inside the bank lobby. In this scene-which viewers watch through a video surveillance monitor-the robbers surround a masked individual. Next, we see the lead robber Dalton Russell shoot this individual and blood disperse as the figure falls to the floor. The robbers use video surveillance to show police-at a safe distance-that they are serious in order to buy more time to accomplish their nefarious aims. In After the Sunset, jewel thief Max Burdett creates a diversion to steal a diamond by framing another character for attempting to steal it, thus preoccupying security officers with the other robbery viewed through video surveillance. It was only near Burdett's mission completion that officers notice his robbery. Here characters are imagined using what Marx (2003) termed "countersurveillance techniques", that is, using surveillance technology against the surveillers. Again, this suggests video surveillance is beneficial not only to officials but to anybody (albeit limited to a great degree by race/ethnicity, class and gender, as discussed below) assumed competent to access or manipulate its presence. 
Hollywood film's depiction of the utility of video surveillance for identification and tracking in film fit common assumptions but, surprisingly, not so for its effective deterrent function. None of the 35 films showed video surveillance effectively or completely deterring perpetrators from illegal or unwanted activity. Even if the system was highly sophisticated-such as in Ocean's Eleven-characters implemented their plan regardless. In other instances, the obvious presence of video surveillance was ignored during a crime of passion. And on several occasions video surveillance enabled crime, including in The Italian Job when a traffic control video surveillance system was hacked to direct a truck carrying gold to a location to be robbed, and as described above, in the Inside Man. Hollywood film does not express video surveillance as a useful deterrent to illegal or unwanted behavior, thus again suggesting that while positive associations with video surveillance are expressed it is nuanced.

\subsubsection{Video Surveillance Need Not Raise Privacy Concerns or Be Resisted}

Hollywood film rarely portrays video surveillance as intrusive, which also normalizes its use. This was consistent across the 35 films. Although several privacy violations were occasionally depicted, they were ignored by characters as such. For example, in Vacancy a privacy violation goes unacknowledged since this violation is the least of the worries of the couple now trapped in their hotel room about to suffer a horrific fate. The violation is minimized due to more serious impending events. In State of Play, a man holds information about a conspiracy involving a corporation deemed valuable to reporters and wants to avoid identification. However, the subsequent violation of his privacy is downplayed due to the alleged importance of this knowledge. The man is no longer seen as a victim but as the valued key to uncovering a conspiracy. In American Pie, the humor created by seeing Jim Levenstein fail sexually leads the viewership to forget the violation of the foreign exchange student's privacy (she was unaware anyone was watching them). She does not even acknowledge the possibility of embarrassment or mortification and by film's end is still communicating with Levenstein. The severe violation is minimized in the comedic context; such a privacy violation via video surveillance is expressed as entertaining and therefore should not raise concern. In his study of several films, Turner (1998, p. 107) had similarly asserted that Hollywood manages to "gloss over the collective anxieties about being spied upon". Overall, these intrusions using video surveillance are minimized, thus helping normalize its use. No films prominently depicted fair notification of video surveillance systems through signage (Lippert, 2009), nor showed the characters using privacy-by-design safeguards (Lippert \& Walby, 2015) via, for example, blurring faces within video surveillance images. Only two films (Enemy of the State and Eagle Eye) of the 35 even noted the deleterious effect on personal privacy that surveillance technologies pose. And while these two films question how much surveillance is necessary, they never express that surveillance of the kinds depicted, including video surveillance, should cease. Thus, although these films at first glance seriously question video surveillance, ultimately they imply it is an inevitable fact of life.

Consistent with the foregoing, twelve films included scenes whereby video surveillance images were neither a preoccupation of characters nor otherwise a focus. Instead video surveillance formed part of the cinematic background. Nothing in these images was plot significant. But this too contributes to normalization. Many of these background images were in security rooms of private companies or government agencies. For instance, in After the Sunset, two FBI agents discuss the possibility of a diamond theft with a ship captain while video surveillance images are evident in the background. In Fracture and Panic Room, video surveillance images flicker in the background of affluent characters' private homes. This use of images constructs video surveillance as normal in workplaces and residences and suggests further that privacy should no longer be expected in these customary private spaces. Video surveillance is prudently already in place to protect against the worst event that might occur there (murder or robbery in the last two films), however unlikely.

Hollywood film does not usually encourage resistance to video surveillance since watchers typically are portrayed using surveillance images appropriately. As noted above, those in authority are usually shown using video surveillance to discover valuable information about suspects. Officials tend not to be depicted abusing their authority by using video surveillance primarily in ways that invade privacy for personal voyeuristic reasons or other immediate self-interest and only secondarily for official business. And those who resist video surveillance tend to do so to protect their criminal identity or otherwise avoid official capture rather than because of a sense of duty to ensure preservation of civil liberties or other ideal principles in the particular institution or broader society.

In nine films, video surveillance was rendered inoperable such that an image was completely inaccessible. This is typically accomplished by blocking, breaking, hacking, or otherwise disabling cameras. For instance, in Salt, Evelyn Salt escapes custody from the CIA's headquarters after being accused of spying. She devises an escape by blocking three video surveillance cameras in succession with fire extinguisher foam, then using her underwear to do likewise, and finally shooting a fifth camera's lens. In our sample, the fact a camera no longer functions typically alarms characters who notice, thus underscoring the importance of video surveil- 
lance to existing routines and arrangements and thus as proper to everyday life. In Hostage Part II, one hostage realizes she is under video surveillance, so to exit the room unnoticed she disables the camera. But the watchers miss seeing this act, leading them to believe events had not transpired as expected. Extra security is summoned. In The Score, two guards stationed in a security room monitor a valuable artifact in a secure area through a video surveillance system's bank of monitors. But several screens suddenly momentarily go dark due to thieves seizing control of the system as one thief slowly maneuvers to steal the artifact without the guards noticing. One security guard blames the outdated system. After several minutes, however, the lead guard becomes suspicious and sends three others to investigate. With guards en route, the surveillance system suddenly is made operational again and the lead guard discerns an unauthorized person in the secure area through a monitor. Viewers learn the system had not malfunctioned; it merely had been purposely hacked. Typically, in the films the cause of concern is ultimately shown to be illegal or illicit activity, rather than the numerous technological malfunctions or limitations inherent to video surveillance, including image transfer (see Walby \& Lippert 2015; Wilkinson \& Lippert, 2012).

The blockage or disabling of a video surveillance system, thus preventing a character's image from being captured and displayed, is a form of resistance that Marx (2003) labels "breaking". Depicting this to some degree fits the notion of film's critical potential in relation to surveillance observed by Kammerer (2004). Yet, such crude resistance is typically not portrayed as administered by an average citizen but instead by criminals avoiding capture. Thus, the films' message is that such crude resistance is an inappropriate way for the upright citizen to respond to harmful effects of video surveillance. Moreover, citizens need not resist video surveillance, unless they have something to hide from authorities. As Hollywood film scenes enter our gaze in theaters and living rooms, and increasingly via new devices (e.g., tablets and smart phones) and websites (e.g., Netflix), they carry with them the proliferating real world "nothing to hide" argument (Solove, 2007) and thus help normalize video surveillance. If you have nothing to hide, why not allow video surveillance to operate, proliferate, and oversee daily life?

\subsubsection{Only Some People Are Video Surveillance Competent}

Surprisingly, in our film sample we found racial/ethnic minorities and women are not disproportionately portrayed as the targets of video surveillance. However, Hollywood film grants disproportionate permission to gaze through video surveillance or to use the visual information in its images to White, middle class, middleaged men, largely excluding minorities and women from the powerful position of watcher or surveiller. The epitome of this is the critically acclaimed Cabin in the Woods, showing for much of the film two professional White men in front of a bank of video surveillance monitors accordingly orchestrating events unbeknownst to the characters. Of 70 pertinent scenes from the 35 films, 61 show White men as watchers, 31 scenes portray only White men, and 43 scenes feature only men of any apparent race as surveillers. Consistent with video surveillance depicted operating in affluent private residences noted above, no lower class persons, as identified through character back stories or their depicted occupations, are portrayed as surveillers. Moreover, racial/ethnic minorities are rarely depicted as surveillers without being accompanied by White men. In our sample women are often depicted as both surveiller and surveillance target but when portrayed as surveillers they are more often accompanied by men rather than watching on their own. Thus, racial/ethnic minorities and women tend to be shown as largely incapable of operating surveillance technology and interpreting the meaning of its images without White men's presence. Similar to Lake's (2010, p. 232) remark about contemporary cinema, Hollywood film tends to restrict who is allowed to watch and thereby limits the power accompanying this vantage point to a select group. Thus, video surveillance may be expressed in positive terms in Hollywood film, but the message is again more nuanced: not everyone can or should be trusted to use it.

\subsubsection{Neglect Video Surveillance and Its Malfunctions at Your Peril}

Often films portray video surveillance capturing events in-the-moment while no characters watch video monitors. But the images characters fail to observe would have served their interests. For example, in Hostage Part II, people bid for the opportunity to harm innocent others. In the killing ground, viewers see a surveillance image of a hostage taking control of her hired assailant while security guards neglect to notice this act in the monitors. This suggests these events were preventable had they been watched; the inability of humans to keep up with video surveillance prevents receipt of valuable information. But the films nonetheless portray video surveillance as a reliable means of accessing the truth and thus worthy of acceptance into everyday life.

In some scenes it is humanly impossible for characters to pay full attention to the surveillance images. For instance, in Snake Eyes, Rick Santoro is sifting through 1,500 video images in a casino's security room to search for a suspect. While he focuses on one surveillance image the person of interest happens to walk through another image directly adjacent to Santoro. In several other films, there is simply no one near to notice the crucial video image. In Inside Man described 
earlier, for instance, Dalton Russell stops video surveillance's functioning in the bank prior to commencing the robbery by using an infrared beam. Concurrently, viewers see the bank's security room where video surveillance is malfunctioning and no security guards present to notice. The utility of the technology is slowed by its operators or eliminated by their absence. Thus, film conveys the notion that video surveillance is limited by human failure (see also Kammerer, 2004) and there is no obvious reason to doubt the effectiveness of video surveillance on its own. However, Hollywood film's very inclusion of humans in these arrangements, befitting Gad and Hansen's (2013) assertion noted above, suggests that surveillance is best understood as a complex assemblage of technology and humans.

Only a few films in the sample express that video surveillance cannot be trusted due to the possible alteration of its images. In Eagle Eye, a computer with artificial intelligence is executing an elaborate plan by manipulating people to murder others. While passing through an airport screening point, a security guard takes her eyes off the x-ray bag scanning screen. At that moment the image is altered to depict random mundane items rather than the characters' syringe injectors, thus allowing the main characters to pass through and avoid capture. Had the screener not looked away, however, she would have noticed this alteration. In Ocean's Eleven, a video surveillance image depicts Linus Caldwell standing in a secure elevator leading to the casino vault he intends to rob. While there, the video surveillance operator is distracted and viewers watch Caldwell's image replaced with an image of an empty elevator. Again, had the operator not been distracted, the image alteration arranged by Ocean and his gang would have been noticed, leading to their apprehension and failure. Scenes expressing any doubt about authenticity were almost evenly distributed between images that were after-the-fact and in-themoment, which contrasts with literature that suggests doubt is observed more often about after-the-fact images (Levin, 2002). But while video surveillance images are at least sometimes portrayed as alterable, this alteration would be noticed only if humans had paid proper attention. Thus, even when alteration occurs, it could be avoided but for human error. This discourse expresses as well the extent of our current reliance on video surveillance technologies such that once they stop functioning one should feel uneasy because it means a harmful act outside routine is afoot. Video surveillance is a technology becoming so embedded in everyday life that concern is apt when witnessing a system "malfunction".

\section{How Hollywood Is Attached to a Video Surveillant Assemblage}

Most previous research takes the flow of Hollywood films for granted, ignoring that this is a key process that constitutes assemblages; if films are unavailable to watch, what they express is irrelevant. Just as there is growing video surveillance in everyday life, the means by which to create and reach a viewership is expanding too. The three "traditional" means of film reaching a viewership are a theater, television (whether via antenna, satellite or cable), and home rental of first videotape and now DVDs of Hollywood films. Now Netflix and similar corporate services deliver Hollywood films chosen by viewers direct to living rooms and onto nearly every new portable device with a screen to be watched in all spaces imaginable. From classrooms to washrooms to public buses to automobiles, Hollywood film can now be watched nearly anytime, anywhere.

Film is both a material link and a communication format; video surveillance images in Hollywood are grafting normalizing expression onto a broader video surveillant assemblage through various means. To the extent films used real video surveillance technology to produce the surveillance images positioned within them (a practice suggested by the distinctive quality of video surveillance images) such as "crudeness, starkness, and graininess" (Doyle, 2006, p. 210) within the larger films, as well as their flickering, shuddering, black and white, and/or dark appearance) that contrast with the film itself (clear, smooth, color, and/or light), this troubles the distinction between the "real" and "the illusory". Indeed, though difficult to establish with certainty, only in a few films did the surveillance images seem simulated, such as in Fracture when the images are undergoing police analysis, rather than being a product of real video surveillance technology. To the extent actual video surveillance technology is used to produce the images this way it serves as a specific instance of Zimmer's (2011) broader point about film as the practice of surveillance and suggests how Hollywood is becoming attached to a surveillant assemblage. This means too there is a sense in which when these images are used in film they are not "fake", since the meaning of that term becomes unclear here. The moment of the surveillance image's arrival in film, is the moment of attachment of Hollywood (and all that term represents with its accompanying institutions of production, marketing and dissemination) film to a broader video surveillant assemblage.

In most films, consistent with the foregoing discourses, video surveillance is also portrayed as having a capacity to access reality, to access the truth consistent with the popular notion that "the camera never lies" and in so doing normalizes its use to achieve this vital multi-purpose function. Hollywood film uses video surveillance images in ways that fit this dominant media logic. Here too the video surveillance image troubles the relation between "the real" and "the illusory". Yet the deployment of surveillance images in this way is potentially unstable and may problematize what it ex- 
presses. This is because the "realness" of the image and the fictional quality of the broader film in which it is placed contrast. Put differently, the aim to render the film more real comes with the contradictory message that all that happens before and after the image is fiction. When it comes to video surveillance, what Hollywood film expresses is not without nuance, nor is it seamless.

\section{Conclusion}

This article has extended previous research, surveillance studies, and film studies by exploring how Hollywood film shapes the understanding of the promotion and reception of video surveillance. Normalization of video surveillance occurs in multifaceted ways in Hollywood film. Undoubtedly this normalization has occurred within film production circles; the use of video surveillance as a filmic device to advance a plot in Hollywood film ${ }^{5}$ has been normalized. But we think normalization is not limited to this: film's wider expressive normalizing effects and material links beyond itself matter too. If Hollywood film is entirely self-referential, it is unclear we ought to study it any more than we might study the content of a closed circuit video surveillance system. By normalization we mean to suggest how video surveillance in film is accepted far beyond film in the broader society as well and becomes part of a broader surveillant assemblage.

From our analysis emerged four dominant discourses. Hollywood expresses that video surveillance can identify and locate people to advantage and need not raise privacy concerns or be resisted by citizens. Only some kinds of people are competent to use video surveillance and everyone neglects its products and "malfunctions" at their peril. These dominant discourses in Hollywood films help facilitate normalization of video surveillance by assigning it positive attributes, albeit not blithely so. Hollywood also expresses that video surveillance can be used to great advantage, usually coupled with other means; it can be resisted (albeit crudely by criminals or immoral persons with something to hide); and it does not deter. However, overall our results support the notion that Hollywood film conveys video surveillance as a necessary and inevitable component of everyday life; surveillance is typically experienced by characters as largely benign and unobtrusive (Murakami-Wood \& Webster, 2009, pp. 266267). These discourses support earlier accounts about the malfunction of surveillance being attributed to human error (Kammerer, 2004) too and that only some people (mostly White, middle-class men) are competent surveillers (Lake, 2010). When the 35 films from across genres are considered together they appear to

\footnotetext{
${ }^{5}$ We thank one of the remarkably helpful anonymous review-
} ers for this point. coincide mostly with Turner's (1998) view of the ideological function of Hollywood film in relation to surveillance.

More broadly the foregoing suggests that film and related media formats are part of surveillant assemblages. Their often coarse scenes scratch away at smooth sheets of trust that used to characterize the liberal democratic institutions and public spaces they depict, laying bare tiny trenches for seeds of suspicion to germinate and grow. Here trust in institutions to adequately manage risk (of every conceivable harmEricson, 2007) and the presumption of innocence of all institutional actors involved in such efforts are replaced with suspicion and pre-emption consistent with a precautionary logic. Accordingly video surveillance is portrayed in film as safely spreading through these newly carved pathways or already positioned to watch for the impending institutional disaster in case it comes that way, however far-fetched its appearance is forecast to be. This message hinders critical analysis, discourages appropriate resistance to video surveillance use and growth in light of its harmful effects, especially on privacy, and facilitates its spread in the wider society. Hollywood film is only one avenue by which video surveillance is normalized, but its increasing incorporation of video surveillance and its vast reach and appeal renders it a significant one. If Hollywood film is becoming discursively and structurally attached to a surveillance assemblage it commences a demand that scholarship draw from both the humanities and the social sciences for adequate understanding of these arrangements. Future scholarship needs to explore dominant discourses in other forms of contemporary popular culture to understand how and why surveillance society continues to so rapidly emerge as well as how to construct alternative critical discourses, informed by privacy principles and humanism.

\section{Acknowledgments}

The authors wish to thank the issue editors and anonymous reviewers for their detailed and exceedingly helpful comments on an earlier draft of this article.

\section{Conflict of Interests}

The authors declare no conflict of interests.

\section{References}

Albrechtslund, A. (2008). Surveillance and ethics in film: Rear window and the conversation. Journal of Criminal Justice and Popular Culture, 15(2), 129144.

Albrechtslund, A., \& Dubbeld, L. (2005). The plays and arts of surveillance: Studying surveillance as entertainment. Surveillance \& Society, 3(2/3), 216-221. 
Andrejevic, M. (2004). Reality TV: The work of being watched. Oxford: Rowman \& Littlefield Publishers.

Andrejevic, M. (2005). The work of watching one another: Lateral surveillance, risk, and governance. Surveillance \& Society, 3(4), 479-497.

Babbie, E., \& Benaquisto, L. (2002). Fundamentals of social research $\left(1^{\text {st }}\right.$ ed.). Scarborough: ThomsonNelson.

Barnard-Wills, D. (2011). UK news media discourses of surveillance. Sociological Quarterly, 52(4), 548-567.

Bauman, Z., Bigo, D., Esteves, P., Guild, E., Jabrie, V., Lyon, D., \& Walker, R. (2014). After Snowden: Rethinking the impact of surveillance. International Political Sociology, 8, 121-144.

Bogard, W. (2006). Surveillance assemblages and lines of flight. In D. Lyon (Ed.), Theorizing surveillance: The panopticon and beyond (pp. 97-122). Devon: Willan Publishing.

Carroll, R. (2013, November 4). California police use of body cameras cuts violence and complaints. The Guardian. Retrieved from http://www.theguardian. com/world/2013/nov/04/california-police-bodycameras-cuts-violence-complaints-rialto

Deleuze, G., \& Guattari, F. (1987). A thousand plateaus. Minneapolis: University of Minnesota Press.

Dinkes, R., Kemp, J., Buam, K., \& Synder, T. (2009). Indicators of school crime and safety: 2009. Washington, DC: National Center for Education Statistics, Institute of Education Sciences, U.S. Department of Education, Bureau of Justice Statistics, Office of Justice Programs, and U.S. Department of Justice.

Doyle, A. (2003) Arresting images: Crime and policing in front of the television camera. Toronto: University of Toronto Press.

Doyle, A. (2006). An alternative current in surveillance and control: Broadcasting surveillance footage of crimes. In K. Haggerty \& R. V. Ericson (Eds.), The new politics of surveillance and visibility (pp. 199224). Toronto: University of Toronto Press.

Doyle, A., Lippert, R., \& Lyon, D. (2012). Introduction. In A. Doyle, R. Lippert \& D. Lyon (Eds.), Eyes everywhere: The global growth of Canada surveillance (pp. 1-19). London: Routledge.

Doyle, A., \& Walby, K. (2012). Selling surveillance: Introduction of videos in Ottawa taxis. In A. Doyle, R. Lippert \& D. Lyon (Eds.), Eyes everywhere: The global growth of Canada surveillance (pp. 185-201). Toronto: Routledge.

Ericson, R. (2007). Crime in an insecure world. Cambridge: Polity Press.

Foucault, M. (1977). Discipline and punish: The birth of the prison. New York: Vintage.

Gad, C., \& Hansen, L. (2013). A closed circuit technological vision: On minority report, event detection and enabling technologies. Surveillance \& Society, 11(1/2), 148-162.

Haggerty K., \& Ericson, R. (2000). The surveillant assem- blage. British Journal of Sociology, 51(4), 605-622.

Haggerty, K. (2006). Tear down the walls: On demolishing the panopticon. In D. Lyon (Ed.), Theorizing surveillance: The panopticon and beyond (pp. 23-45). Cullompton: Willan.

Jamieson, P., \& Romer, D. (2014). Violence in popular U.S. prime time TV dramas and the cultivation of fear: A time series analysis. Media and Communication, 2(2), 31-41.

Kammerer, D. (2004). Video surveillance in Hollywood movies. Surveillance \& Society, 2(2/3), 464-73.

Kammerer, D. (2012). Surveillance in literature, film and television. In D. Lyon, K. Haggerty, \& K. Ball (Eds.), Routledge handbook of surveillance studies (pp. 99-106). New York, NY: Routledge.

Lake, J. (2010). Red Road (2006) and emerging narratives of "sub-veillance". Continuum: Journal $f$ Media \& Cultural Studies, 24(2), 231-240.

Levin, T. (2002). Rhetoric of the temporal index: Surveillance narration and the cinema of "real time". In T. Levin, U. Frohne, \& P. Weibel (Eds.), CTRL [space]: The rhetorics of surveillance from Bentham to Big Brother (pp. 578-593). Cambridge, MA: MIT Press.

Lippert, R. (2009) Signs of the surveillant assemblage: Urban CCTV, privacy regulation and governmentality. Social and Legal Studies, 18(4), 505-522.

Lippert, R., \& Wilkinson, B. (2010). Capturing criminals, crime, and the public's imagination: assembling crime stoppers and CCTV Surveillance. Crime, Media, Culture, 6(2), 131-152.

Lippert, R. \& Walby, K. (2015). Governing through privacy: authoritarian liberalism, privacy law, and privacy knowledge. Law, Culture, and the Humanities, 13(1), early online version.

Lyon, D. (2002). Editorial. surveillance studies: Understanding visibility, mobility and the phenetic fix. Surveillance \& Society, 1(1), 1-7.

Lyon, D. (2007). Surveillance studies: An overview. Cambridge: Polity Press.

Marks, P. (2005). Imagining surveillance: Utopian visions and surveillance studies. Surveillance \& Society, 3(2), 222-239.

Marx, G. (2003). A tack in the shoe: Neutralizing and resisting the new surveillance. Journal of Social Issues, 59(2), 369-390.

McCahill, M. (2003). Media representations of visual surveillance. In P. Mason (Ed.), Criminal visions: Media representations of crime and justice (pp. 192-213). Devon: Willian Publishing.

Monahan, T. (2006). Questioning surveillance and security. In T. Monahan (Ed.), Surveillance and security: Technological politics and power in everyday life (pp. 1-23). New York: Routledge.

Monahan, T. (2010). Surveillance in the time of insecurity. New Brunswick: Rutgers University Press.

Monahan, T. (2011). Surveillance as cultural practice. 
The Sociological Quarterly, 52, 495-508.

Murakami-Wood, D. (2013). What is global surveillance? Towards a relational political economy of the global surveillant assemblage. Geoforum, 49, 317-26.

Murakami-Wood, D., \& Webster, C. (2009). Living in surveillance societies: The normalization of surveillance in Europe and the threat of Britain's bad example. Journal of Contemporary European Research, 5(2), 259-273.

Murakami-Wood, D., \& Webster, C. (2011). The normality of living in surveillance societies. Information Technology and Law Series, 20(3), 151-164.

Norris, C., \& Armstrong, G. (1999). The maximum surveillance society: The rise of CCTV. Oxford: Berg.

Rose, G. (2007). Visual methodologies: An introduction to the interpretation of visual materials ( $2^{\text {nd }}$ ed.). Los Angeles: Sage.

SCAN (2009). Surveillance camera awareness network-A report on video surveillance in Canada. Kingston, Canada: The Surveillance Project, Queen's University.

Solove, D. (2007). "I've got nothing to hide" and other misunderstandings of privacy. San Diego Law Review, 44, 745-772.

Stewart, G. (2012). Surveillance camera. Film Quarterly,
66(2), 5-15.

Turner, J. (1998). Collapsing the interior/exterior distinction: Surveillance, spectacle, and suspense in popular cinema. Wide Angle, 20(4), 93-123.

Verga, S. (2010). Closed-circuit TV surveillance evaluation: statistical analysis of the effects on rates of crime. Ottawa, Canada: Technical Report. Defense Research and Development Canada, Centre for Security Science.

Walby, K. (2006). Little England? The rise of openstreet closed-circuit television surveillance in Canada. Surveillance \& Society, 4(1/2), 29-51.

Walby, K., \& Lippert, R. (2015). Municipal corporate security in international context. New York: Routledge.

Wilkinson, B., \& Lippert, R. (2012). Moving images through an assemblage: Police, visual information, and resistance. Critical Criminology, 20, 311-325.

Zeilinger, M. (2012). Appropriation and the authoring function of video surveillance in Manu Luksch's Faceless. In A. Doyle, R. Lippert, \& D. Lyon (Eds.), Eyes everywhere: The global growth of Canada surveillance (pp. 262-273). London: Routledge.

Zimmer, C. (2011). Surveillance cinema: Narrative between technology and politics. Surveillance \& Society, 8(4), 427-440.

\section{About the Authors}

\section{Dr. Randy K. Lippert}

Randy K. Lippert is Professor of Criminology at the University of Windsor, Windsor, Canada where he teaches in the areas of policing and security, surveillance, and socio-legal studies. He is currently debates editor for the international journal Surveillance and Society and Thinker-in-Residence at Deakin University in Geelong, Australia. He has published more than 60 refereed articles and chapters and six books, including, Policing Cities: Urban Securitization and Regulation in a $21^{\text {st }}$ Century World (2013) and Municipal Corporate Security in International Perspective (2015), both with Kevin Walby.

\section{Jolina Scalia}

Jolina Scalia is a researcher with the Government of Alberta, Canada. She holds an Honors B.A. in criminology and psychology and an M.A. in criminology from the University of Windsor, Windsor, Canada. 
Appendix 1. The Hollywood film sample.

1. 15 Minutes. Directed by John Herzfeld, 2001.

2. 21. Directed by Robert Luketic 2008.

3. After the Sunset. Directed by Brett Ratner, 2004.

4. American Pie. Directed by Paul Weitz, 1999.

5. The Bourne Ultimatum. Directed by Paul Greengrass, 2007.

6. Dawn of the Dead. Directed by Zack Snyder, 2004.

7. Eagle Eye. Directed by D.J. Caruso, 2008.

8. Enemy of the State. Directed by Tony Scott, 1998.

9. Fracture. Directed by Gregory Hoblit, 2007.

10. Hall Pass. Directed by Bobby Farrelly and Peter Farrelly, 2011.

11. Hostel Part II. Directed by Eli Roth, 2007.

12. Inside Man. Directed by Spike Lee, 2006.

13. The International. Directed by Tom Tykwer, 2009.

14. The Italian Job. Directed by F. Gary Gray, 2003.

15. Knight and Day. Directed by James Mangold, 2010.

16. The Manchurian Candidate. Directed by Jonathan Demme, 2004.

17. Ocean's Eleven. Directed by Steven Soderbergh, 2001.

18. Panic Room. Directed by David Fincher, 2002.

19. A Perfect Getaway. Directed by David Twohy, 2009.

20. Salt. Directed by Phillip Noyce, 2010.

21. Saw II. Directed by Darren Lynn Bousman, 2005.

22. The Score. Directed by Frank Oz, 2001.

23. Showtime. Directed by Tom Dey, 2001.

24. Snake Eyes. Directed by Brian De Palma, 1998.

25. Spy Games. Directed by Tony Scott, 2001.

26. State of Play. Directed by Kevin Macdonald, 2009.

27. Street Kings. Directed by David Ayer, 2008.

28. Traitor. Directed by Jeffrey Nachmanoff, 2008.

29. Vacancy. Directed by Nimród Antal, 2007.

30. Vantage Point. Directed by Pete Travis, 2008.

31. Dark Skies. Directed by Scott Stewart, 2013.

32. Cabin in the Woods. Directed by Drew Goddard, 2012.

33. Paycheck. Directed by John Woo, 2003.

34. The Judge. Directed by David Dobkin, 2014.

35. Run All Night. Directed by Jaume Collet-Serra, 2015. 